\title{
OCULAR MANIFESTATIONS OF NOONAN SYNDROME
}

\author{
N. B. LEE, L. KELLY, M. SHARLAND \\ London
}

\begin{abstract}
SUMMARY
Noonan syndrome is a genetic condition inherited in an autosomally dominant manner, characterised by congenital heart disease, short stature, abnormal facies and the somatic features of Turner's syndrome, but a normal Karyotype.

The ophthalmological and orthoptic findings on 58 patients with Noonan syndrome are reported. External features were hypertelorism (74\%), downward sloping palpebral apertures $(38 \%)$, epicanthic folds $(39 \%)$ and ptosis $(\mathbf{4 8 \%})$. The orthoptic examination revealed strabismus in $48 \%$, refractive errors in $61 \%$, amblyopia in $33 \%$, and nystagmus in $9 \%$ of cases.

Sixty-three per cent of cases had anterior segment changes consisting of: Prominent corneal nerves $(46 \%)$, anterior stromal dystrophy (4\%), cataracts $(8 \%)$ and panuveitis (2\%). Fundal changes occurred in $20 \%$ of the study group, including optic nerve head drusen, optic disc hypoplasia, colobomas and myelinated nerves.

Forty-seven per cent required non surgical treatment and a further $16 \%$ had undergone surgery for strabismus or ptosis. Only three patients had no visual defects. With such a high incidence of ophthalmic abnormalities it is clearly important that children with Noonan syndrome are screened by an ophthalmologist at an early age.

The diagnosis of Noonan syndrome is made purely on clinical grounds. Unlike Turner's syndrome, which is phenotypically similar, no chromosomal abnormalities have been detected. The lack of any laboratory test to confirm the diagnosis has hampered the recognition of this syndrome. The first case was probably described by Kobyliniski ${ }^{1}$ in 1883 but such cases were varyingly called Status Bonnevie Ullrich or 'Male Turner's syndrome'. It was not until 1963 that Dr. Jacqueline Noonan ${ }^{2}$ identified this group as a separate condition. Opitz ${ }^{3}$ subsequently proposed the name Noonan syndrome to avoid further confusion. The key to the diagnosis is an individual with

From: Ophthalmology Department, St. George's Hospital, Blackshaw Road, London SW17 0QT.

Correspondence to: Mr. Nicholas Lee FRCS, FCOphth, Ophthalmology Dept., St. George's Hospital, Blackshaw Road, London SW17 0QT.
\end{abstract}

typical facies (Fig. 1), right sided cardiac abnormalities and normal chromosomes. The main features of the 151 patients seen by the multidisciplinary team, including the 58 patients reviewed here, are listed in Table I. This variability of expression led to a suggestion that a scoring system should be introduced to aid the diagnosis ${ }^{4}$, and this was used to confirm the diagnosis in the study group patients.

This syndrome has an autosomal dominant pattern of inheritance with a high (about 50\%) new mutation rate. It

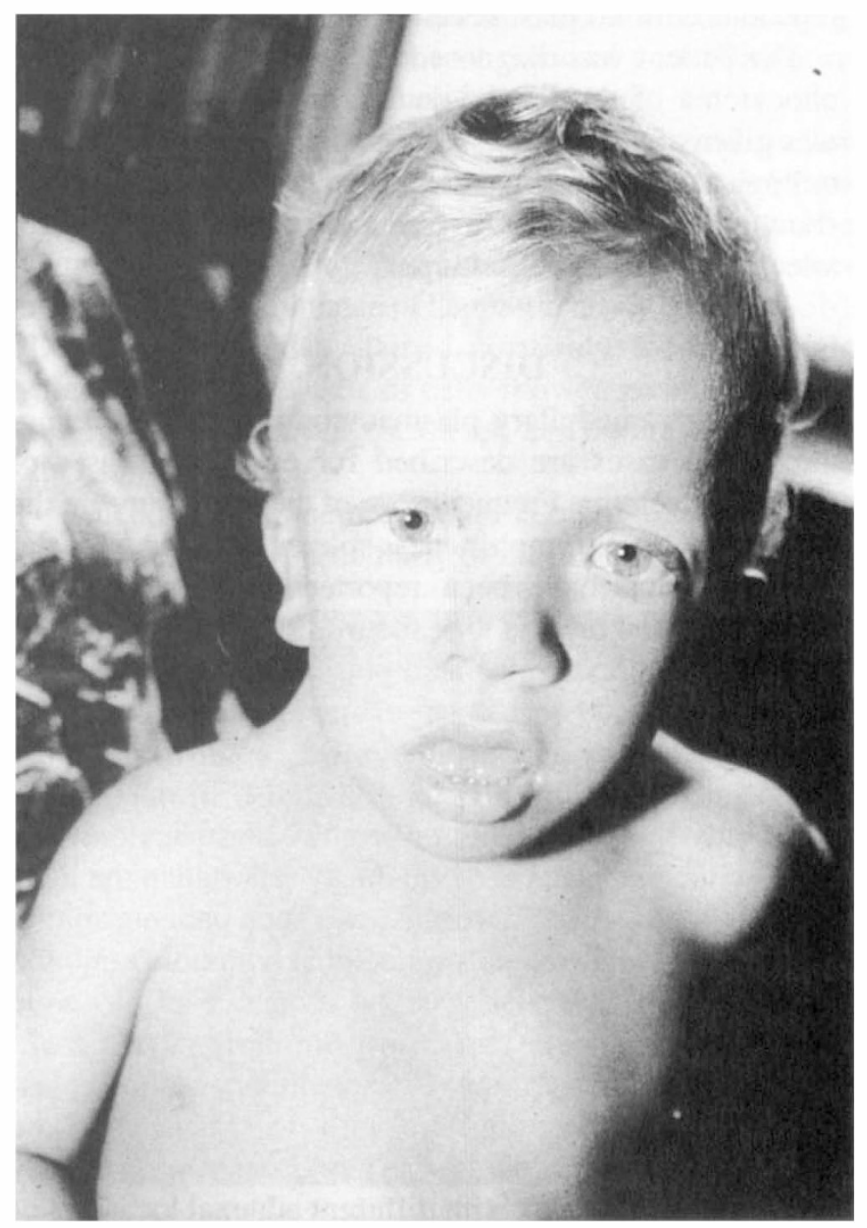

Fig. 1. Noonan Child. 
Table I. Main General features of Noonan Syndrome found in 151 individuals examined

\begin{tabular}{ll}
\hline Feature & $\%$ \\
\hline Cardiac Defect & 88 \\
Pulmonary Stenosis & 62 \\
Hypertrophic Cardiomyopathy & 20 \\
ASD, VD, AVD & 13 \\
Cardiac Surgery & 20 \\
Skeletal & \\
Chest Abnormalities (Pectus carinatus superior & \\
\& Pectus excavatum inferior) & 95 \\
Joint Hyperextensibility & 50 \\
Webbed Neck & 22 \\
Short stature-Mean Bone delay & 2.0 years \\
Skin \& Hair & 67 \\
Prominent Fetal Pads on hands and toes & 40 \\
Abnormal hair (Thick \& curly or sparse) & \\
Schooling & 84 \\
Attending Normal School & \\
Other & 67 \\
Undescended Testes & 95 \\
Feeding difficulties & 58 \\
Bleeding abnormalities & 26 \\
Hepatosplenomegaly & 38 \\
Hearing Loss (Otitis Media) & \\
\hline
\end{tabular}

Table II. Summary of the External Facies observed in 58 patients with Noonan Syndrome. Where less than 58 patients were examined, the number examined is indicated in parentheses

\begin{tabular}{lrr}
\hline External Feature & No. & $\%$ \\
\hline Hypertelorism & 43 & 74 \\
Downward Sloping palpebral apertures & 22 & 38 \\
Epicanthic Folds & $22(56)$ & 39 \\
Ptosis & $22(56)$ & 48 \\
Lower Lid Retraction & $2(56)$ & 4 \\
Proptosis & $1(56)$ & 2 \\
Orthoptic Findings & & \\
Strabismus & 28 & 48 \\
$\quad$-Esotropia & 13 & 22 \\
$\quad$-Exotropia & 10 & 17 \\
$\quad$-Mixed & 1 & 2 \\
$\quad$-Vertical & 4 & 7 \\
Abnormal Binocular Vision & 21 & 36 \\
Amblyopia & $18(55)$ & 33 \\
Nystagmus & 5 & 9 \\
Head Turn & 1 & 2 \\
Refractive Errors & $33(57)$ & 61 \\
\hline
\end{tabular}

\section{Angle}

Degrees

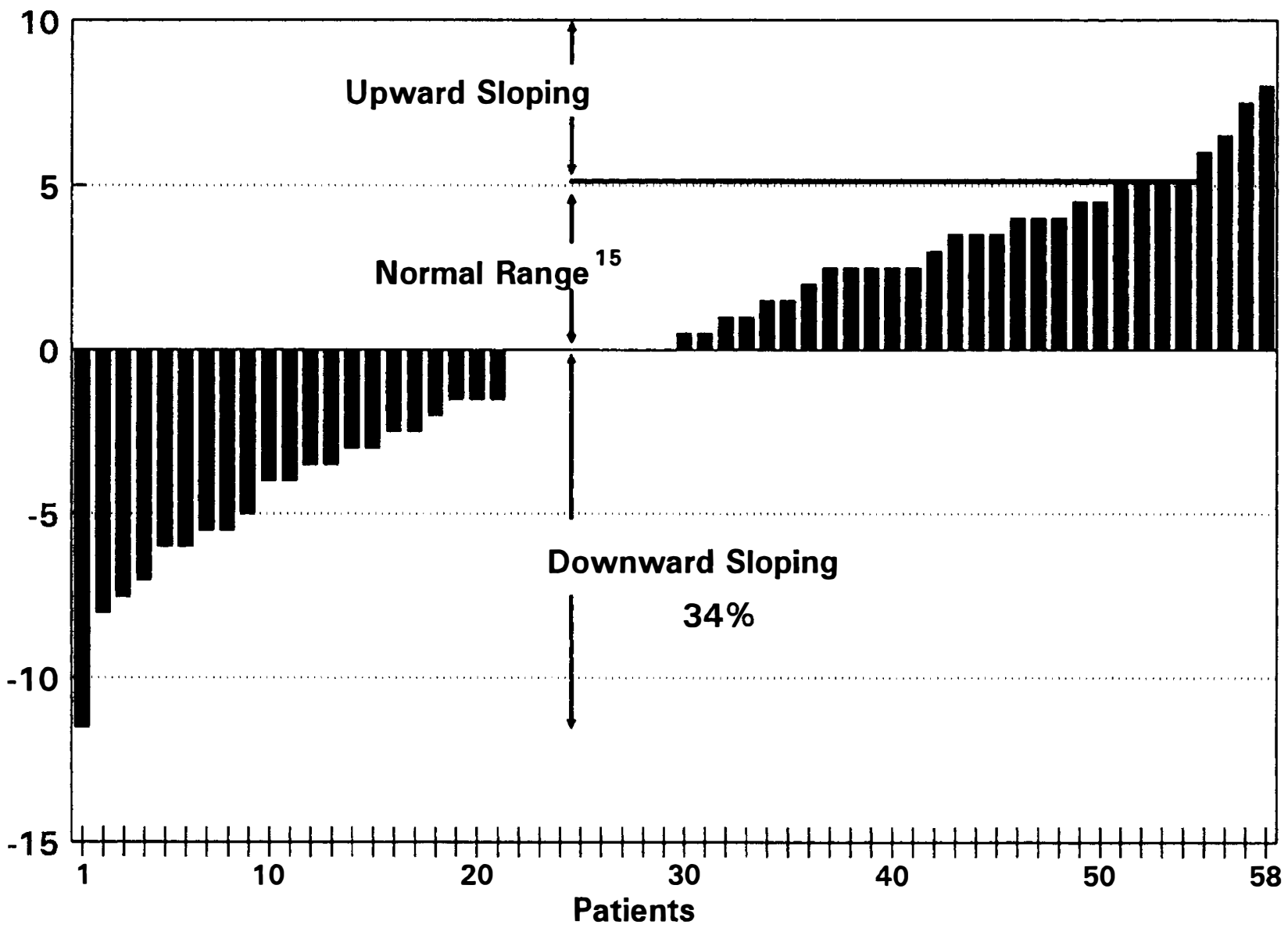

Fig. 2. Histogram showing the range of palpebral fissure angles. The mean angle for the two eyes is shown. The normal range is taken as $0-5$ Degrees. ${ }^{15}$ 
Diopters

Cylinders

Best Vision Sphere

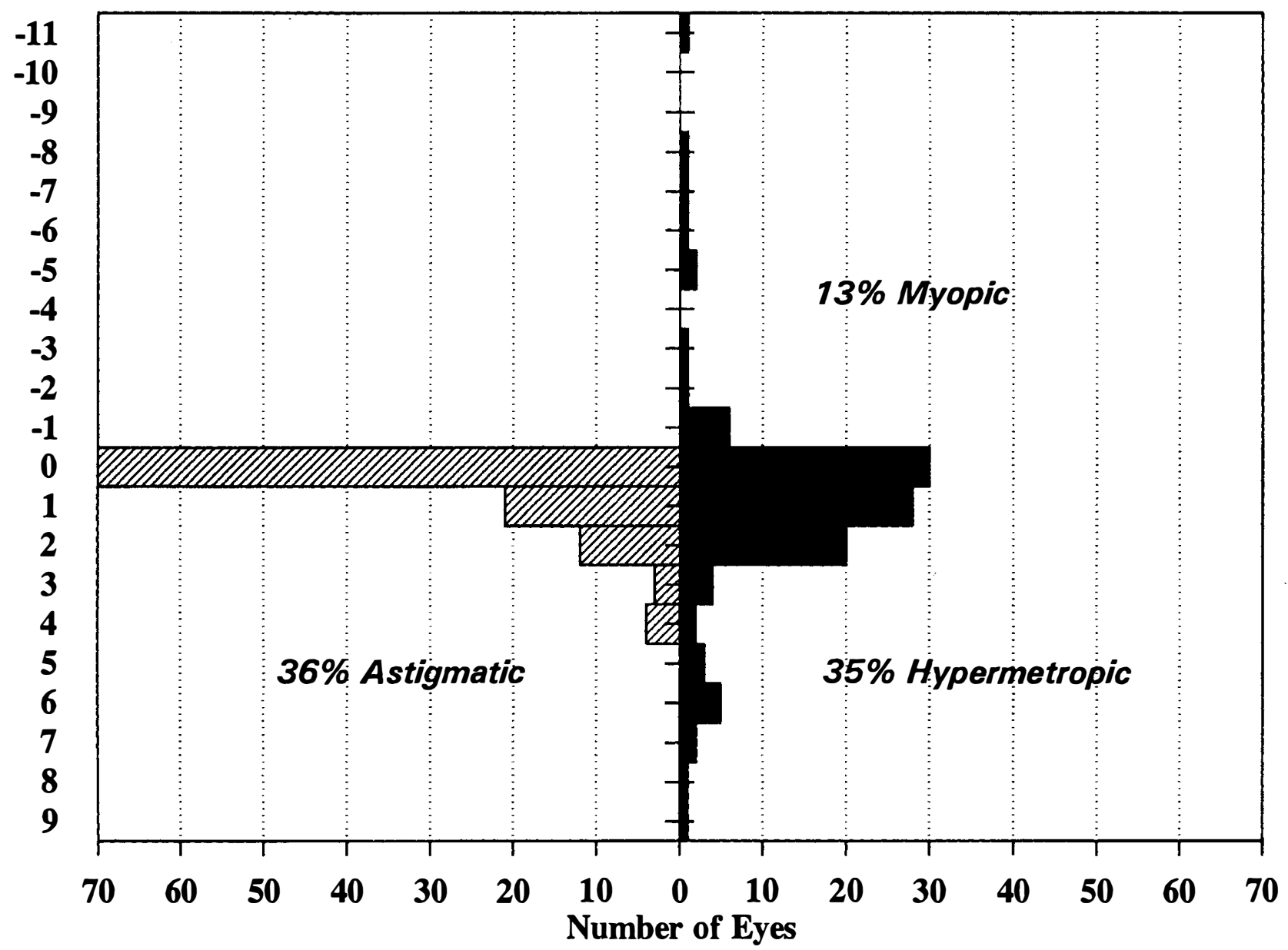

Fig. 3. Histogram showing the range of refractive errors.

is common to find minor anomalies or partial expression of this syndrome in other family members. The exact incidence of Noonan syndrome is unknown but has been estimated at between one in 1000 and one in 2500 live births ${ }^{5}$ for severely affected cases. When Mendez and Opitz ${ }^{6}$ reviewed the literature they found that eye abnormalities were the commonest consistent finding being present in

Table III. Ophthalmic findings observed with Noonan Syndrome. The number of patients examined is in parentheses

\begin{tabular}{|c|c|c|}
\hline Ophthalmic Findings & No. & $\%$ \\
\hline Anterior Segment Changes & $30(48)$ & 63 \\
\hline Panuveitis & 1 & 2 \\
\hline Corneal Pannus formation & 4 & 8 \\
\hline Peripheral Sclero-cornea & 1 & 2 \\
\hline Corneal Opacity & $2 "$ & 8 \\
\hline Prominent Corneal Nerves & $22 "$ & 46 \\
\hline Persistent Pupillary Membrane & 1 & 2 \\
\hline Cataract & $1(53)$ & 2 \\
\hline Marked Lens Vacuolation & $10(53)$ & 6 \\
\hline Fundal Abnormalities & $10(51)$ & 20 \\
\hline Coloboma disc or retinal & 2 & 4 \\
\hline Swollen discs/Disc Drusen & 2 & 4 \\
\hline Myelinated Nerves & 1 & 2 \\
\hline Optic Disc Hypoplasia & $2 "$ & 4 \\
\hline Situs Invertus & 1 & 2 \\
\hline Tortuous Vessels & 3 & 6 \\
\hline
\end{tabular}

$95 \%$ of the 121 individuals reviewed. Reports in the ophthalmic literature have been limited to individual case reports. ${ }^{7,8,9}$ This study was undertaken to produce a comprehensive review of the ocular features of Noonan syndrome.

\section{METHOD}

This study was conducted as part of a larger multi-disciplinary research project into Noonan syndrome. To recruit patients a letter was sent to all consultant paediatricians, paediatric cardiologists and clinical geneticists in the United Kingdom, asking for the names of any patients with Noonan syndrome under their care and permission to contact their families. The first 58 patients recruited were included in this study. The diagnosis of Noonan syndrome was confirmed by the paediatrician (MS) who also used a scoring system ${ }^{4}$ to aid diagnosis. A full orthoptic examination was conducted by the senior orthoptist (LK), and included visual acuity assessment, autorefraction, cover test, synoptophore and stereo acuity. A facial photograph was taken to measure the inner canthal to zygomatic ratio, ${ }^{10}$ and the angle of the palpebral fissures. If the former ratio exceeded 0.28 (97th Percentile from a group of normal children) this was considered indicative of hyper- 


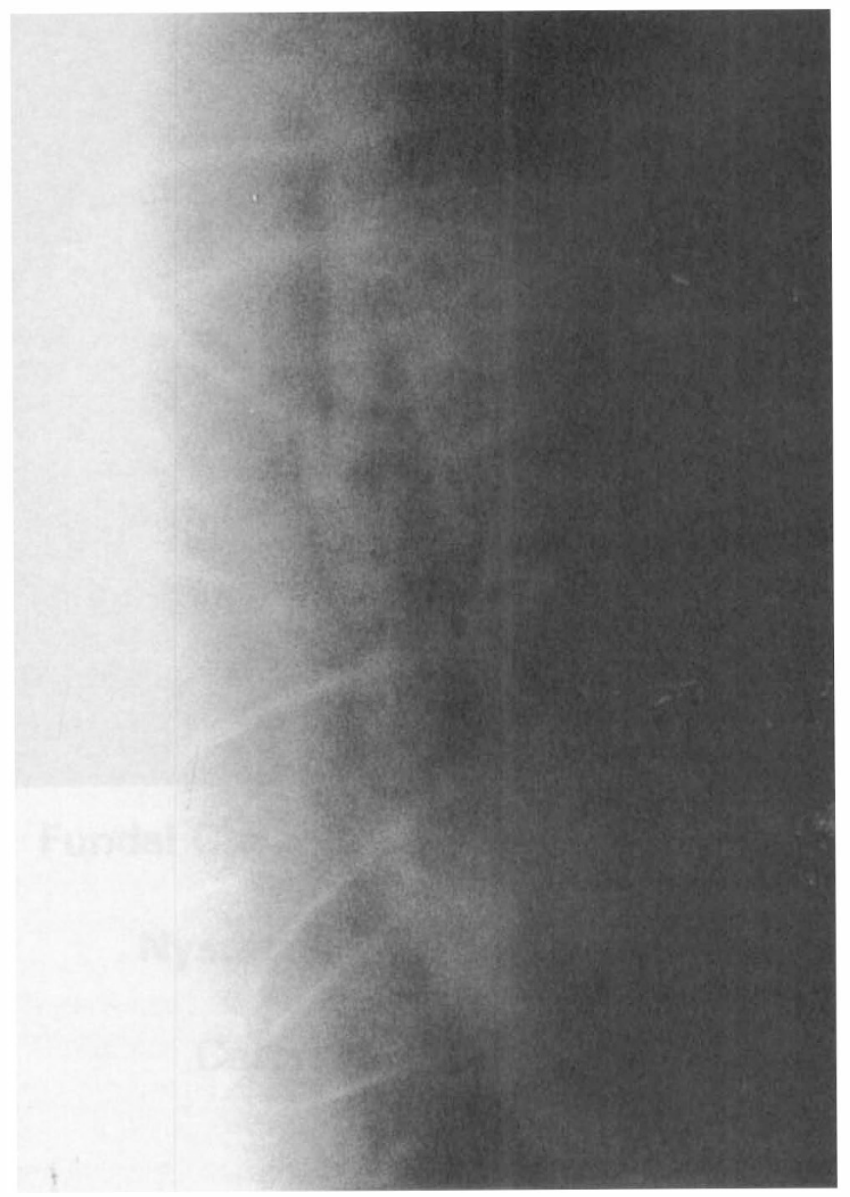

Fig. 4. Prominent corneal nerves. A similar appearance is found all the way round the limbus in both eyes. They can easily be traced to the central corneal region.

telorism. The ophthalmic examination commenced with a subjective or objective refraction with cycloplegia (Cyclopentolate hydrochloride $1 \%$ ) where appropriate. A significant refractive error was taken to be hypermetropia greater than +2.00 Dioptres, myopia greater than -0.75 Dioptres and astigmatism greater than \pm 1.00 Dioptre. This was followed by an external examination and a slit-lamp examination. All patients then underwent a mydriatic fundal examination (using g. Tropicamide $1 \%$ \& g. Phenylephrine hydrochloride $10 \%$ if Cyclopentolate had not already been instilled.)

\section{RESULTS}

The age of the study patients ranged from one year to 40 years with a mean age of 10 years. $83 \%$ were less than 16 years old. Thirty-three were males and 25 females. The main external features are listed in Table II. Of the 58 patients in this study, all underwent the paediatric and orthoptic examination, though in three cases it was not possible to accurately assess visual acuity. Furthermore, one case failed to attend for any refractive assessment, two failed to attend for the external and internal ophthalmic examination and five failed to return for their post mydriatic fundal examination. In 10 cases, including the two who failed to attend this part of the examination, it was not possible to examine them on the slit-lamp. The results have been adjusted to take account of this and where the case numbers are less than 58 the number actually examined is indicated in parentheses. The most consistent finding was hypertelorism which was documented in 43 cases. Epicanthic folds of the epicanthus palpebralis type were present in 22 (of 56) cases. The palpebral fissures were downward sloping in 21 patients (Fig. 2) but varied between -11.5 and $+8^{\circ}$.

Ptosis was present in 27 cases of which 16 measured at least $2 \mathrm{~mm}$. The ptosis was usually symmetrical. In three cases ptosis surgery had been undertaken. Manifest strabismus was present in 28 cases of which $46 \%$ were esotropia, $36 \%$ exotropia, $14 \%$ had a vertical element and $4 \%$ were mixed. Of the 21 with abnormal binocular function, eight showed no potential for binocular vision at any distance, six had established anomalous retinal correspondence and seven had intermittent strabismus with suppression. Amblyopia defined as occurring when there is a reduction of two or more lines on the Snellen chart, was present in 18 (of 55) cases. Refractive errors of all types were common and the spectrum of refractive errors is shown in Figure 3.

A variety of abnormalities in the anterior and posterior segments were identified and these are listed in Table III. Increased visibility of the corneal nerves was seen in 22 (of 48) patients. The number and extent of the nerves that were visible varied between patients but was similar between the two eyes of one individual. The nerves were most visible nearest the limbus and became more translucent as they approached the central cornea. In 13 of these 22 patients there were more than 10 nerve fibres visible at the limbus and at least one extended into the central cornea. The most advanced case had a corneal dystrophy beside an extensive number of prominent corneal nerves (Fig. 4) that extended into the central region. The anterior stroma had a granular appearance that was more marked centrally. In addition in the anterior stroma there were small discrete circular areas of marked granularity. The appearances were similar in both eyes. Corneal sensation was intact and the visual acuity was unaffected. The corneas of the child's parents were normal. The appearance of the corneal dystrophy remained unchanged over the next two years. In the second patient similar discrete opacities were present on the endothelium in a geographic area just above the visual axis in one eye only. The rest of the anterior chamber in both of these patients was normal. Changes in the lens were noted in four (of 53) patients. A moderately dense asymmetric mixed nuclear and cortical cataract was noted in a severely affected 14 month old who had severe pulmonary stenosis that required a pulmonary valvotomy. In three others marked vacuolation of the lens was noted.

Fundal changes (Table III) were present in 10 (of 51) cases and only interfered with vision in one case. Both of the children with the optic disc hypoplasia were severely affected by the Noonan syndrome and difficult to examine. The first case of optic disc hypoplasia was in a seven year old child. The vision was reduced to $6 / 18$ right and 


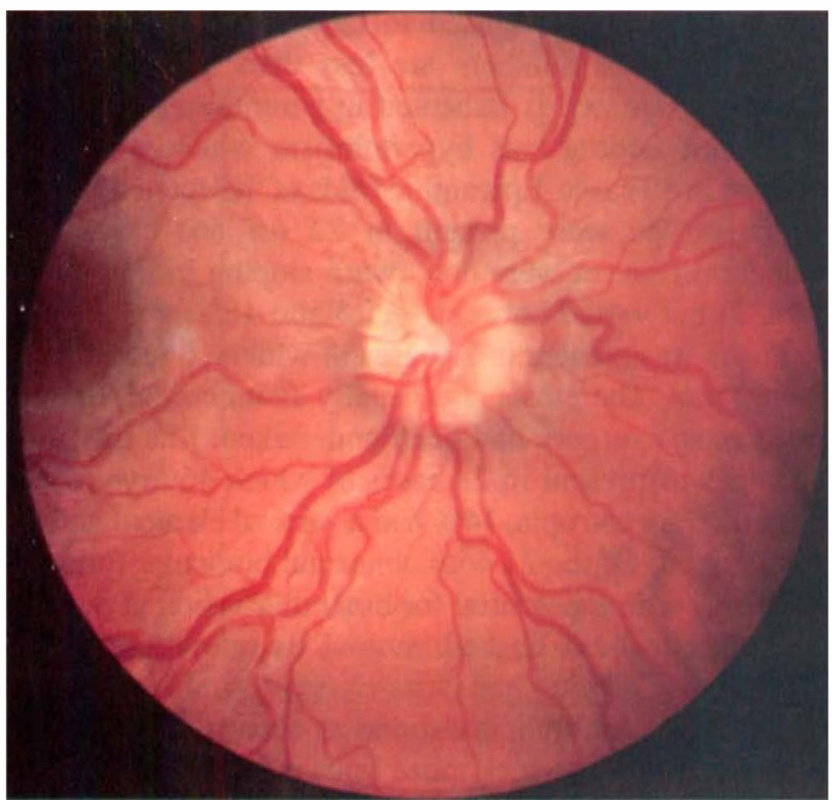

(a)

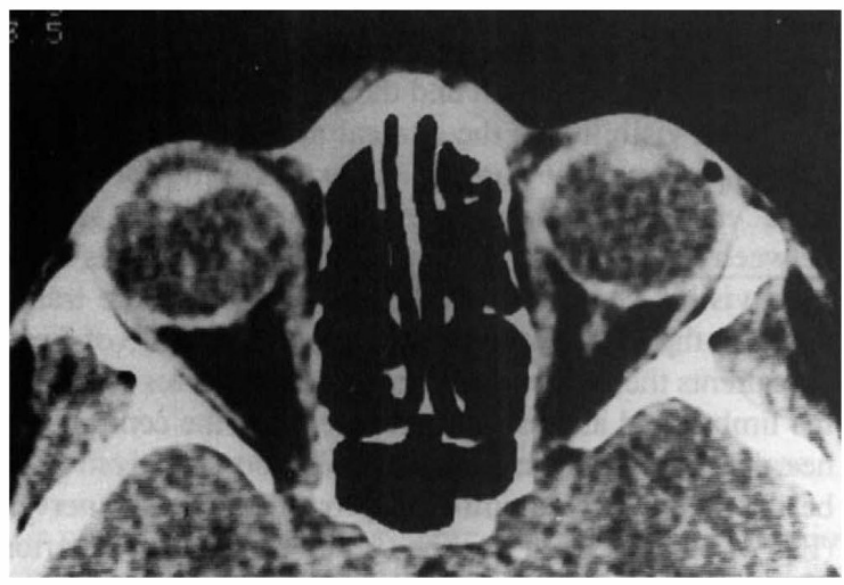

(c)

6/36 left with mixed astigmatism. Confrontational fields showed an inferior field defect. He also had bilateral ptosis, horizontal nystagmus and prominent corneal nerves. Computerised axial tomography of the ventricles and basal cisterns was normal as was an ERG. The second case was 19 years old. The vision could only be measured with a Catford Drum because his concentration and co-operation was so poor. This was found to be reduced to $6 / 18$. He has undergone two squint operations for a convergent squint. No further investigations have been carried out. In two cases swollen optic discs were observed consistent with buried optic disc drusen. Bilateral deep intra-retinal haemorrhages that formed partial rims around the optic discs were present in the first case (Fig. 5). A CAT scan confirmed the presence in the second case. Fluorescein angiography confirmed the absence of a neovascular complex in both cases.

\section{DISCUSSION}

This study agrees with the findings of Mendez and Optiz that ocular abnormalities are one of the commonest and

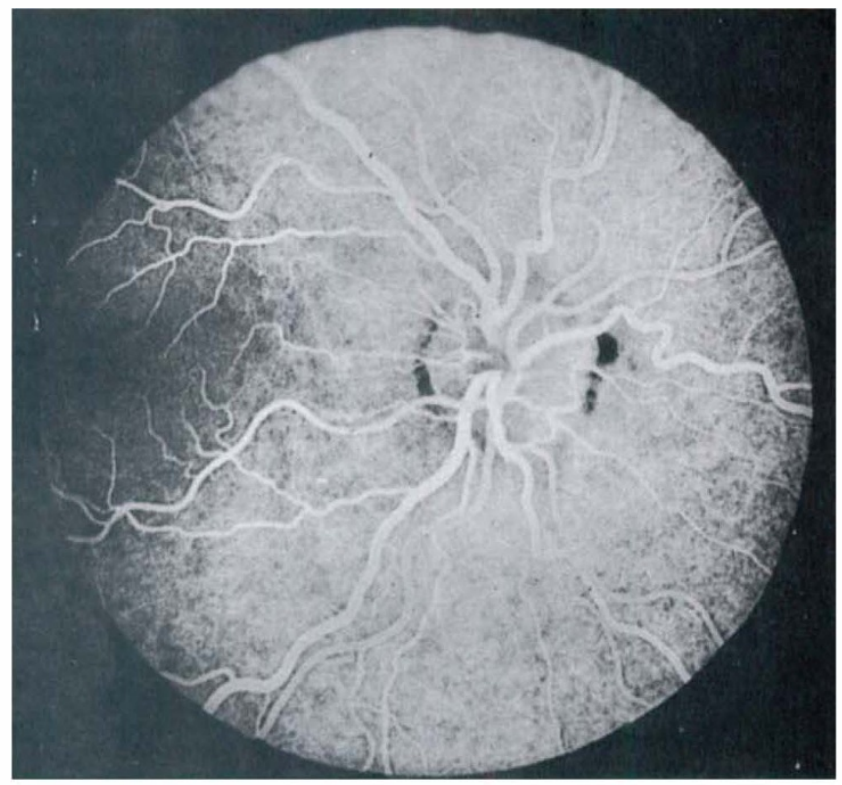

(b)

Fig. 5. Buried Optic Disc Drusen. (a) \& (b) Colour photograph and fluorescein Angiogram showing haemorrhage around the Disc. (c) CAT scan showing the bilateral Optic disc Drusen.

most consistent features of Noonan syndrome occurring in our series in $95 \%$ of all cases. A similar spectrum of ocular features have been documented in Turner's and Down's syndromes and would appear to be part of the manifestations of craniofacial malformations (Fig. 5). Distinguishing features of Noonan syndrome include a higher incidence of ptosis, downward rather than the upward slanting palpebral fissures which occur in Down's sydrome and the presence of prominent corneal nerves. Though the overall incidence of strabismus in the three syndromes is similar, esotropia predominates in Turner's and Down's syndrome ( $84 \%$ and $90 \%$ respectively $\left.{ }^{11-16}\right)$, whereas this made up only $48 \%$ of our study group.

Corneal abnormalities consisting of corneal opacities were known to occur in Turner's syndrome, ${ }^{12}$ and were observed in two Noonan syndrome patients. However, prominent corneal nerves were found in $54 \%$ of the patients and is a new finding in Noonan syndrome. Neurofibromatosis is known to occur more commonly in Noonan patients ${ }^{17}$ than the general population and prominent corneal nerves are known to occur in $65 \%$ of such 


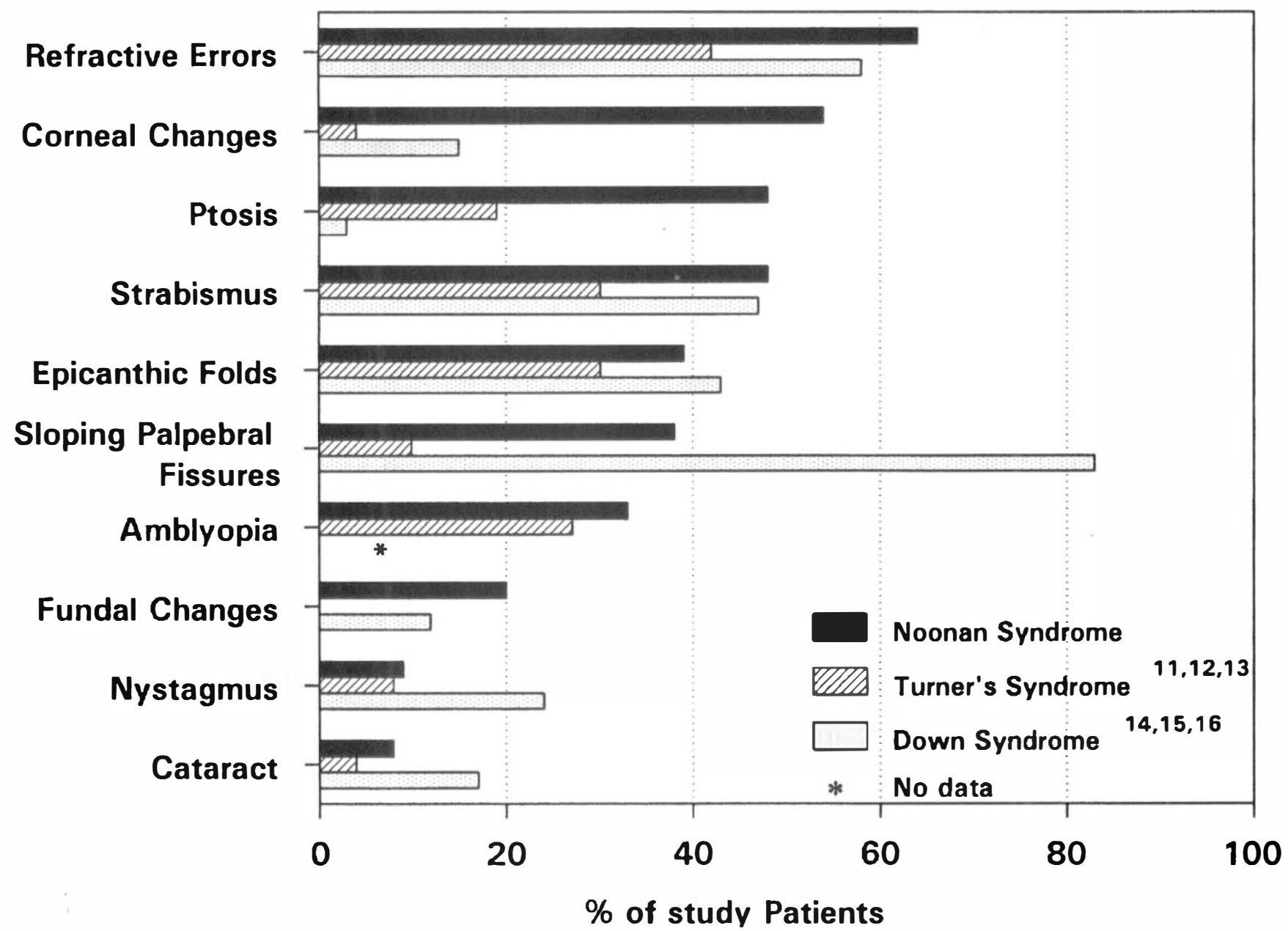

Fig. 6. Comparison of the main ophthalmic features of Noonan, Turner and Down's Syndromes.

patients. ${ }^{18}$ However, only one patient of ours had neurofibromatosis and there were no visible corneal nerves in this case. Because of this association between neurofibromatosis and Noonan syndrome and the discovery of similar corneal nerves, gene linkage studies with the neurofibromatosis I locus were undertaken. However no linkage was found. There is little pathological information explaining why the corneal nerves become prominent.

Table IV. Management Summary. Orthoptic treatment consisted of occlusion therapy and does not include those patients who are just attending the orthoptic department for review. The findings of those patients who had not previously attended an ophthalmic department are also presented

\begin{tabular}{lrr}
\hline & No. & $\%$ \\
\hline Surgery & $\mathbf{9}$ & $\mathbf{1 6}$ \\
Squint & 5 & \\
Ptosis & 3 & \\
Syringe \& Probing & 1 & \\
Non-Surgical Treatment & $\mathbf{2 7}$ & $\mathbf{4 7}$ \\
Spectacles & 22 & 9 \\
Orthoptic Treatment & 5 & $\mathbf{5 2}$ \\
Attended Eye Department & $\mathbf{3 0}$ & $\mathbf{4 8}$ \\
Never seen by eye Department & $\mathbf{2 8}$ & 39 \\
Normal Eye examination & 11 & 22 \\
Undetected Refractive error & 6 & 32 \\
Undetected Squint & 9 & 7 \\
Ptosis & 2 & \\
\hline
\end{tabular}

Bleshoy ${ }^{19}$ showed that in patients with keratoconus the nerves appeared thickened due to a change in the basement membrane around what appeared normally structured nerves. The increased prominence does not seem to alter their function as no patients in our study group appeared to have reduced corneal sensitivity. As the stromal dystrophy was observed in the case which had the greatest number of prominent corneal nerves, it may be that the dystrophy is a result of the abnormal corneal nerves.

Of the 58 patients, $27(47 \%)$ required non surgical treatment predominantly consisting of prescribing glasses and occlusion therapy for amblyopia. A further nine (16\%) had undergone surgery for strabismus, ptosis or blocked nasolacrimal duct (Table IV). Of concern to us was the observation that 28 of the patients had not attended an ophthalmology department before. Amongst this group 17 $(61 \%)$ were found to have either a refactive error, including a myope of -6.25 , a hypermetrope of +8.5 and a child with a +4.50 cylinder, or a significant squint or ptosis. It is likely that because these children often have serious cardiac and feeding problems when young this overshadows any ocular problems the child may have. Only one of the 58 patients appeared to be below normal intelligence and was attending a special school. Most of the other children were of normal intelligence and were attending normal schools. This makes the detection and correction of the 
above conditions especially important to ensure that they realise their full potential.

In summary $95 \%$ of patients with Noonan syndrome had some ocular abnormality. Amongst these there is a considerable variety of disorders found, but the most frequent are hypertelorism, refractive errors, strabismus and anterior segment changes including prominent corneal nerves and less commonly cataracts and fundal changes. With such a high incidence of ocular abnormalities, it is clearly important for all children with Noonan syndrome to have a detailed visual assessment in infancy.

We wish to thank the Noonan Syndrome Society and the Lewis Charitable Trust for their support of this research. We would also like to acknowledge the ophthalmologists and orthoptists at St. George's Hospital for their help in assessing these children and research nurse Maureen Morgan and secretary Linda Hill for their help.

Key words: Amblyopia, Cataracts, Corneal Nerves, Corneal Dystrophy, Down's Syndrome, Epicanthic Folds, Hypertelorism, Myelinated Nerves, Neurofibromatosis, Optic Disc Drusen, Palpebral Apertures, Ptosis, Squint, Strabismus, Turner's Syndrome, Uveitis, Noonan Syndrome, Nystagmus.

\section{REFERENCES}

1. Koblylinksi O: Uber eine flughautähnliche Ausbreitung am Haise. Arch Anthropol 1883, 14: 342-811.

2. Noonan JA and Ehmke DA: Associated non-cardiac malformations in children with Congenital heart disease. $J$ Paed 1963, 63: 468-70.

3. Optiz JM, Summitt RL, Sarto GE: Noonan's Syndrome in girls: A genocopy of the Ullrich-Turner syndrome. J Pediatr 1965, 67: 968.

4. Duncan et al: A comprehensive scoring system for eval- uation Noonan Syndrome. Am J Med Genet 1981, 10: $37-50$.

5. Nora JJ and Freaser FC: Medical Genetics: principles and practice. 2nd ed. Philadelphia: Lea and Febiger, 1981.

6. Mendez HM and Opitz JM: Noonan Syndrome: A review. Am J Med Genet 1985, 212: 493-506.

7. Calder IG and Willshaw HE: Noonan's syndrome in association with Brown's superior oblique tendon sheath syndrome. Brit Orthopt J 1984, 41: 58-9.

8. Kleanthous L, D'Cruz, D, Graham, E, Efthimiou J: Colobomata associated with Noonan's syndrome. Postgrad Med $J$ 1987, 63: 559-61.

9. Schwartz DE: Noonan's Syndrome associated with ocular abnormalities. Am J Ophthalmol 1972, 73: 955-9.

10. Stengel-Rutkowski S, Schimanek $P$, Wernheimer A: Anthropometric definitions of dysmorphic facial signs. Hum Genet 1984, 67: 272-95.

11. Chrousos GA et al: Ocular findings in Turner Syndrome. Ophthalmology 1984, 91: 926-8.

12. Lessell S and Forbes A: Eye signs in Turner's Syndrome. Arch Ophthalmol 1966, 76: 211-13.

13. Adhikary HP: Ocular manifestations of Turner's Syndrome. Trans Ophthalmol Soc UK 1981, 101: 395-6.

14. Caputo AR, Wagner RS, Reynolds DR, Guo S, Goel AK: Down's Syndrome. Clinical Review of Ocular Features. Clin Paed 1989, 28: 355-8.

15. Shapiro MB and France TD: The Ocular Features of Down's Syndrome. Am J Ophthalmol 1985, 99: 659-63.

16. Yamashita $S$, Nakamura $S$, Kakimotos $S$, Nakamura $T$ : Ocular findings in Down's Syndrome. Jap J Clinophthal 1973, 27: 1292-99.

17. Opitz JM and Weaver DD: The neurofibromatosis-Noonan Syndrome. Am J Med Genet 1985, 21: 477-90.

18. Huson S, Jones D, Beck L: Ophthalmic manifestations of neurofibromatosis. Br J Ophthalmol 1987, 71: 235-8.

19. Bleshoy H: Sensitivity and neuropathology in the Keratoconic Cornea: PHD. City University, Northampton Square, London. 1990. 